\title{
LECTURA TEOLÓGICA DE LA «VERBUM DOMINI» DE BENEDICTO XVI
}

DOI: https://doi.org/10.52039/seminarios.v57i199-200.353

Prof. SAlVADOR PIÉ-NINOT ${ }^{1}$

INTRODUCCIÓN GENERAL

Dos años después del Sínodo de los Obispos sobre «La Palabra de Dios en la vida y la misión de la Iglesia» (5-26 de octubre de 2008), Benedicto XVI publica la Exhortación Apostólica Postsinodal La Palabra del Señor (Verbum Domini) el 11 de noviembre del mismo año, aunque con fecha de 30 de septiembre del 2010, fiesta de san Jerónimo. Nótese que Benedicto XVI cita en esta Exhortación todas y cada una de las cincuenta y cinco proposiciones conclusivas votadas por las dos terceras partes de los Padres sinodales, y más que responderlas las sitúa en un marco amplio, dejando así preparado su camino de realización concreta ${ }^{2}$.

Téngase presente que este tipo de documento del Magisterio papal es novedoso, ya que se ha forjado a partir del Sínodo de los Obispos, que es una institución creada a raíz del concilio Vaticano II. La característca de una Exhortación Apostólica Postsinodal subraya su carácter de documento conclusivo a partir del correspondiente Sínodo, y su perspectiva no es directamente teológico-asertiva, sino más bien teológico-exhortativa de carácter pastoral «persuasivo», a la que corresponde un «asentimiento religioso del espíritu» (LG 25) 3 .

El mismo título Verbum Domini presenta la particularidad de inscribir el texto en continuidad con la Dei Verbum, calificada como «punto de referencia en el camino eclesial» (VD 3), citada en treinta ocasiones y, por tanto, el corazón de la doctrina parte de esa Constitución, siendo la Exhortación Apostólica cuarenta y cinco años después la que saca consecuencias para la misión de la Iglesia hoy

1. Profesor de la Facultat de Teologia de Catalunya (Barcelona) y de la Pontificia Università Gregoriana (Roma); experto del Sínodo La Palabra de Dios en la vida y la misión de la Iglesia.

2. Cf. sobre el Sínodo de 2008: El Sínodo sobre la Palabra de Dios, Barcelona 2009, con nuestros balances, «El Sínodo de los obispos, de 2008, sobre la Palabra de Dios», Phase 292 (2009) 283-308, y «Nota sobre el Sínodo sobre la Palabra de Dios en vida y la misión de la Iglesia», Gregorianum 90 (2009) 859-864, y el texto de Benedicto XVI, La palabra del Señor. Exhortación Apostólica postsinodal «Verbum Domini», Barcelona 2010, con nuestro comentario: "Los seis temas teológicos de la 'Verbum Domini'», Phase 302 (2011) 123-145.

3. Sobre este tipo de documento y su valor magisterial, cf. S. Pié-Ninot, Eclesiología, Salamanca ${ }^{2} 2009,508$.

4. Cf. Id., «La constitución dogmática Dei Verbum. Breve relectura a 40 años del Concilio Vaticano II», en La Teología Fundamental, Salamanca ${ }^{72009,663-676, ~ y ~ « D e ~ l a ~ D V ~ a l ~ S i ́ n o d o ~}$ de los obispos sobre la Palabra de Dios del 2008», Estudios Eclesiásticos 83 (2008) 223-237. 


\section{Salvador Pié-Ninot}

En efecto, la Palabra que es Dios procede primeramente de Dios, pero inmediatamente toca a la Iglesia ponerla en práctica. Por esto, la expresión escogida, Verbum Domini, es primeramente litúrgica ya que es la aclamación que en el rito latino sigue a la proclamación del Evangelio durante la Misa. Todo ello signo de que la Palabra de Dios no puede ser comprendida fuera de la vida de la Iglesia y debe ser acogida en la liturgia y la plegaria.

Nótese que la fórmula latina Verbum Dei/Domini que la Vulgata usa para calificar particularmente la palabra de Dios que es la Escritura, también la aplica, aunque de forma más limitada, a Jesucristo. Ahora bien, la progresiva pérdida de la lengua latina como lengua de referencia ha conllevado mayoritariamente la desaparición del uso de la misma fórmula Verbum Dei/Domini para la Escritura y para el mismo Verbo encarnado, que favorecía la sinonimia, dado que las traducciones han optado generalmente por usar como equivalencia la expresión palabra (tanto las lenguas latinas: parole, parola, paraula...; como las lenguas sajonas: Word, Wort...). Tan sólo algunas versiones han mantenido la fórmula enraizada en la expresión latina de Verbo: así, en castellano: las clásicas de la BAC: Nácar-Colunga y Bover-Cantera; en francés: la prestigiosa, Bible de Jérusalem, aunque no seguida en su versión castellana, y la ecuménica, Traduction Oecuménique de la Bible (TOB); en catalán: la Bíblia de Montserrat; se inclinan también por esta forma dos traducciones oficiales recientes destinadas a convertirse en normativas para los textos litúrgicos de sus países: la Nuova versione ufficiale della Conferenza Episcopale Italiana del 2009, y la Biblia de la Conferencia Episcopal Española del 2011.

El plan propuesto en tres capítulos no es indiferente para la interpretación del texto: la Palabra de Dios, la Palabra en la Iglesia y la Palabra para el mundo. Propuesta que conviene entender bien: la Palabra no se reduce a la Biblia: se trata sobre todo del Lógos mismo, el Verbo eterno encarnado en Jesús el Cristo. Por eso se sigue el hilo conductor de los escritos de Juan bajo el eje de la comunión-koinônia que abre la DV 1, y también marca VD 2 así: «os anunciamos la vida eterna, que está con el Padre y que se nos ha manifestado. Lo que hemos contemplado, lo que habemos oído, os lo anunciamos también, para que también vosotros estéis en comunión con nosotros. Y nosotros estamos en comunión con el Padre y con su Hijo, Jesucristo» (1 Jn 1, 2-3). Tal perspectiva queda confirmada por el uso del Prólogo de Juan descrito como una «referencia constante» para entrar en la inteligencia del texto y por esto sus versículos sirven de títulos de las tres partes de la VD: Jn 1, 1.14, para la primera; Jn 1, 12, para la segunda y Jn 1, 18, para la tercera.

Según la expresión del mismo Papa, el tema de esta Exhortación «es en cierto sentido el corazón mismo de la vida cristiana, en continuidad con la Eucaristía» (VD 3). Lo ha escogido «para revalorizar la Palabra divina en la vida de la Iglesia... para que ella sea cada vez más el corazón de toda actividad eclesial» (VD 1). En efecto, «no hay prioridad más grande que ésta: abrir de nuevo 
al hombre de hoy el acceso a Dios, al Dios que habla y nos comunica su amor para que tengamos vida abundante (cf. Jn 10, 10)» (VD 2).

Ya que estamos en una Exhortación se afirma: «exhorto a los Pastores de la Iglesia y a los agentes de pastoral a esforzarse en educar a todos los fieles a gustar el sentido profundo de la Palabra de Dios» (VD 52). De ahí que esta Exhortación sea fruto del «gran impulso que la Constitución dogmática Dei Verbum ha dado a la revalorización de la Palabra de Dios en la vida de la Iglesia» (VD 3) y por esto quiere «renovar la fe de la Iglesia en la Palabra de Dios» (VD 27), que haga posible «incrementar la 'pastoral bíblica', no en yuxtaposición con otras formas de pastoral sino como animación bíblica de toda la pastoral. No se trata, pues, de añadir algún encuentro en la parroquia o la diócesis, sino de lograr que las actividades habituales se interesen realmente por el encuentro personal con Cristo que se comunica en su Palabra» (VD 73).

\section{BREVE COMENTARIO Y NOTAS TEOLÓgICAS A LA VERBUM DOMINI}

Introducción (VD 1-5): se presenta con una formulación inicial muy indicativa marcada por el interés en subrayar la fuente de renovación eclesial que supone la Palabra de Dios, así como su carácter central en la Iglesia, y por eso se afirma que «deseo indicar algunas líneas fundamentales para revalorizar la Palabra divina en la vida de la Iglesia, fuente constante de renovación, deseando al mismo tiempo que ella sea cada vez más el corazón de toda actividad eclesial» (VD 1). Después de recordar la Dei Verbum (VD 3) y el Sínodo de los Obispos sobre la Palabra (VD 4), se presenta «el Prólogo del Evangelio de Juan como guía» ya que «se trata de un texto admirable, que nos ofrece una síntesis de toda la fe cristiana» a partir del «discípulo al que Jesús amaba (Jn 13, 23; 20, 2; 21, 7.20)», del cual se recuerdan dos momentos a imitar: cuando «vió y creyó» (Jn 20,8) y cuando reclinó la cabeza sobre el pecho de Cristo (cf. Jn 13, 25) «del que brotaron sangre y agua (cf. Jn 19, 34)». Por eso se concluye brillantemente que «siguiendo el ejemplo del apóstol Juan y de otros autores inspirados, dejémonos guiar por el Espíritu Santo para amar cada vez más la Palabra de Dios» (VD 5).

I. La Primera parte: Verbum Dei (VD 6-49), subtitulado con Jn 1, 1.14: «En el principio ya existía el Verbo/Palabra, y el Verbo estaba junto a Dios, y el Verbo era Dios... y el Verbo se hizo carne»; se trata de la parte más propiamente teológica de con los siguientes puntos sobresalientes:

1. La Analogía de la Palabra de Dios (VD 7): «los Padres sinodales han hablado de un uso analógico del lenguaje humano en relación con la Palabra de Dios... 'el cristianismo es la religión de la Palabra de Dios, no de una palabra escrita y muda, sino del Verbo encarnado y vivo' (san Bernardo)...; es preciso que, desde el punto de vista teológico, se profundice en los diferentes significa- 


\section{Salvador Pié-Ninot}

dos de la Palabra de Dios, para que resplandezca mejor la unidad del plan divino y el puesto central que ocupa en él la persona de Cristo».

* Nota sobre la analogía de la Palabra: esta calificación del uso analógico de la expresión Palabra de Dios está prácticamente ausente en los tratados teológicos a ella referidos. Su empleo reciente, particularmente en el Sínodo de «La Palabra de Dios» de 2008 en su Proposición $n^{\circ} 3$, es obra de uno de sus expertos sinodales, E. Bianchi, prior del Monasterio de Bose, que al comentar este empleo en Orígenes recuerda la pluralidad de significados del texto bíblico como ejemplo de uso analógico, así como la forma de encarnación del Lógos que es análoga al cuerpo físico de Cristo ${ }^{5}$.

J. Ratzinger ya había subrayado que «el concepto de Logos recibe una nueva acepción al aplicarlo a Jesús de Nazaret. El concepto de Logos, que para los griegos significa inteligencia (ratio), se cambia realmente en 'palabra' (verbum). Quien aquí está, es palabra» ${ }^{6}$. El teólogo moderno que se ha aproximado más a esta perspectiva es el reformado K. Barth (1886-1968), con su amplia presentación de la triple forma de la Palabra de Dios: revelada, escrita y predicada, que tiene su centro en la primera que es Jesucristo ${ }^{7}$.

2. El liber naturae desplegado en la «dimensión cósmica de la Palabra» (VD 8) y en «La creación del hombre» (VD 9): aparece aquí el desarrollo del clásico «libro de la naturaleza», que es citado dos veces (VD 7.13).

* Nota sobre el 'Liber naturae': al tratar del uso analógico de la Palabra de Dios, se ha afirmado que «hay que reconocer también que la misma creación, el liber naturae, forma parte de esta sinfonía a varias voces en que se expresa el único Verbo» (VD 7). Más adelante, se presenta esta bella síntesis con la cita de un autor emblemático: "podemos comparar el cosmos a un libro -así decía Galileo Galilei- y considerarlo como obra de un Autor que se expresa mediante la 'sinfonía' de la creación. Dentro de esta sinfonía se encuentra, en cierto momento, lo que en lenguaje musical se llamaría un 'solo', un tema encomendado a un solo instrumento o a una sola voz, y es tan importante que de él depende el significado de toda la ópera. Este 'solo' es Jesús... El Hijo del hombre resume en sí la tierra y el cielo, la creación y el Creador, la carne y el Espíritu. Es el centro del cosmos y de la historia, porque en él se unen sin confundirse el Autor y su obra» (VD 13).

Este liber naturae se expresa en cierto modo, y aunque sea muy austeramente, ya en el Antiguo Testamento, cuando la contemplación de la belleza de la creación conduce a una alabanza entusiasta bien expresada en: «el cielo proclama la gloria de Dios, el firmamento pregona la obra de sus manos» (Sal 19, 1; cf. 89, 6-15; 104). Por eso, hay una antigua tradición del pensamiento cristiano que habla de los «dos libros» de Dios: el de la naturaleza y el de la revelación. Así lo dice bellamente san Agustín: «es libro para ti la Sagrada Escritura, para que la oigas; y es libro para ti el orbe de la tierra, para que lo veas» ${ }^{8}$.

5. Cf. Ascoltare la Parola. Bibbia e Spirito, Comunità di Bosè 2008, 11.14.105.

6. Introducción al cristianismo (1968), Salamanca ${ }^{11} 2005,160$.

7. Dogmatique I/2, Genève 1953, § 4 (pp. 85-120), obra en la que dedica más de mil páginas a la teología de la Palabra de Dios; en cambio, en la tradición católica tal reflexión ha sido escasa, cf. nuestro «Palabra de Dios», en R. Latourelle-R. Fisichella-S. PIÉ-NINOT (eds.), Diccionario de Teología Fundamental, Madrid ${ }^{3} 2010,1044-1046$ (sólo en la edición española).

8. In Ps 45, 7: PL 36, 518. 
Finalmente, se puede observar que sobre esta cuestión el Padre de la Iglesia citado por VD y, prácticamente de forma única, es san Buenaventura, cuyas referencias a sus obras recuerdan la tesis de habilitación de J. Ratzinger sobre este autor donde concluye subrayando «el carácter de signo que tiene toda la creación, ya que Buenaventura abandona todo lo que no es más que una 'teología física' griega, cuya renovación no apoyada en la Bibla es a menudo y de buena gana reprochada a la Theologia naturalis católica. La alabanza de Buenaventura al Dios creador crece totalmente dentro de la religiosidad de los salmos; la herencia griega, que tampoco rechaza, ha entrado aquí toda entera al servicio de la fe cristiana» ${ }^{9}$.

3. La Cristología de la Palabra (VD 11-13): se trata de la formulación teológica central y más novedosa de toda la Exhortación respecto al desarrollo del Sínodo. Como explicación se pone de relieve el testimonio de los Padres que calificaban a Jesús como Verbum abbreviatum (VD 12s), cual Palabra/Verbo de Dios breve, abreviada y sustancial (cf. Is 10, 23 y Rom 9, 23).

* Nota sobre la Cristología de la Palabra: esta formulación teológica central de la DV subraya que la clave de toda la teología de Palabra de Dios es Jesucristo. Por esto, orienta su aplicación a los contenidos mismos de la Tradición y Escritura, así: «aunque el Verbo de Dios precede y trasciende la Sagrada Escritura, en cuanto inspirada por Dios, contiene la palabra divina (cf. 1Tm 3, 16) 'en modo singular» (VD 17), ya que «a través de todas las palabras de la Escritura, Dios sólo dice una Palabra, su Verbo único o Palabra única, en la cual el se dice totalmente» (cf. Heb 1, 1-3) (cf. CEC, $\mathrm{n}^{\circ}$ 102)» (VD 18).

Todo este enfoque novedoso por su incorporación explícita a esta Exhortación recuerda a K. Barth con su 'concentración cristológica' de la que se deriva una teología de la Palabra de Dios desplegada como cristología consecuente cuando escribe: «una dogmática eclesial debe ser cristológica si su único criterio es la Palabra de Dios revelada, atestiguada por la Escritura santa y predicada por la Iglesia, y si es verdad que este Palabra de Dios revelada es idéntica a Jesucristo... La sana reacción cristocéntrica ha de permitir un redescubrimiento verdaderamente auténtico y fecundo del sentido de Juan 1, 14. ¡Se debe ser cristocéntrico desde el inicio!» ${ }^{10}$.

La fórmula "Cristología de la Palabra» puede recordar también una breve anotación de Joseph Ratzinger cuando habla de «la cristología del Logos, como teología de la palabra, como apertura del ser a la idea de relación, ya que siempre es verdad que la palabra procede esencialmente 'de alguien' y se dirige 'a alguien'» ${ }^{11}$.

Como explicación de tal enfoque, VD pone de relieve el testimonio de los Padres que calificaban a Jesús, de forma totalmente original, con la expresión clásica de Verbum abbreviatum (VD 12s.), cual Palabra breve, abreviada, sustancial, «ya que escucha y obedece la Palabra del Padre (cf. Jn 8, 55; 12, 50; 17, 8), sigue la «palabra de la cruz» (1 Cor 1, 18), en el Misterio Pascual realizado 'según las Escrituras'» (1Cor 15, 3s.). La base concreta de esta fórmula del Verbum abbreviatum surge del texto profético de Is 10,23 , retomado en Rom 9, 23, que tiene este tenor: «Dios ha cumplido su palabra y la ha abreviado».

9. La teología de la historia de san Buenaventura (1959), Madrid 2004, 144s.

10. Dogmatique 1/12/1, Genève 1954, 114.

11. Introducción al cristianismo, 161. 


\section{Salvador Pié-Ninot}

4. Tradición viva y Escritura (VD 17-18): siguiendo la Dei Verbum se repite significativamente tres veces el adjetivo «viva/viviente», expresión que consagró uno de los iniciadores de la renovación de la eclesiología en el siglo XIX, J. A. Möhler, La unidad en la Iglesia (1825), al escribir que la «fuerza viva espiritual que se propaga y hereda en la Iglesia es la tradición» (§3:5), por esto «si se toma la tradición como el evangelio vivo, el que se predica precisamente en la Iglesia, con todo lo que entra en esa predicación...; en tal caso, no entendemos la sagrada Escritura sin la tradición, puesto que tampoco sin ella fue dada los fieles» $(\S 16: 6)^{12}$.

Por esto, la adjetivación de «viva» es aplicado con toda precisión a la Tradición en este texto que retoma la DV así: «La sagrada Escritura como testimonio inspirado de la revelación que, junto con la Tradición 'viva', es la regla suprema de la fe (cf. DV 21)» (VD 18). Con todo, a pesar de esta repetida adjetivación de «viva», la VD trata la Tradición de manera más bien austera, dado el vacío teológico postconciliar sobre este tema. En efecto, una vez lograda la laboriosa e importante síntesis conciliar de DV $9^{13}$, faltan criterios sobre la Tradición y los estudios sobre ella son más bien escasos. Esta situación ha comportado un olvido de los lugares teológicos y las calificaciones teológicas, lo que ha conllevado no sólo menos claridad en el ámbito teológico, sino también en el ámbito eclesial, dada la imprecisión que esto ha comportado, ya que sin discernimiento, la tradición tiene el riesgo de convertirse en restauración y llevar al inmovilismo.

5. La inspiración y la verdad de la Biblia (VD 19): referencia clave al debate sinodal y por esto recordando «la conexión entre el tema de la inspiración y el de la verdad de las Esrituras» (VD 19), se cita el texto base de la DV 11: «la verdad que Dios hizo consignar en dichos libros para nuestra salvación», complementado más adelante al subrayar con precisión que no se trata de un «dictado palabra por palabra» (VD 44).

* Nota sobre la inspiración y la verdad de la Biblia: tema y relación que centran la atención partiendo del texto decisivo, aunque quizá poco difundido y profundizado, de DV 11 para el que afirmar la inspiración significa que la Escritura comunica no una verdad cualquiera (geográfica, biológica, histórica...) sino «la verdad que Dios hizo consignar en dichos libros para nuestra salvación». Esta precisión sobre la «verdad para la salvación» como contenido positivo de la inspiración ayuda a entender qué significa Palabra de Dios: se trata de aquella palabra que sólo Dios puede pronunciar porque comporta la salvación que sólo Dios puede dar.

En esta precisión conciliar se manifiesta la particular 'auto-implicación' y 'palabra última' que expresa la Escritura como Palabra de Dios, en este caso, soteriológica, porque interpela, asume y salva la condición histórica-limitada-y-abierta al futuro de la persona

12. La unidad en la Iglesia, Pamplona 1996, 103 y 139; cf. nuestro, «La tradición como viva vox evangelii», Diálogo Ecuménico 34 (1999) 287-297.

13. Cf. nuestra síntesis, La Teología Fundamental, 603s.669-672. 
humana. Por esto, a la Escritura se le llama con razón «palabra de Dios» por su singular relevancia en transmitir y proclamar la Palabra de Dios sobre la salvación, con una autoimplicación y ultimidad que se desplegó de forma fundante para todos los tiempos en el reconocimiento y fijación del Canon. Tal calificación de palabra de Dios, es decir, 'inspirada', le viene dada de forma singular porque es un testimonio y una presencia única de tal palabra a estos tres niveles: por su origen, ya que surgió bajo la acción del Espíritu; por su cualidad interna, ya que está llena del Espíritu, y por su dimensión experiencial, ya que comunica el Espíritu ${ }^{14}$.

Por eso, se pide más profundización e investigación sobre esta relación, dado el riesgo de caer en una lectura fundamentalista de la Biblia que entienda la inspiración «como si hubiera sido un dictado palabra por palabra» (VD 44). Esta perspectiva ya quedó precisada en el concilio Vaticano II en la forma de tratar la historicidad de los Evangelios, la cual, siguiendo la Instrucción de la Pontificia Comisión Bíblica de 1964 (cf. DH 44024407), afirma que los Evangelios son testimonios fieles sobre Jesús teniendo presente que «los Apóstoles transmitieron lo que Jesús dijo e hizo, iluminados por una comprensión más plena gracias a la Pascua y al Espíritu Santo»; por eso, concluirá que la tarea realizada por los Evangelistas (de selección, síntesis y adaptación) tenía como objetivo transmitir «lo verdadero y lo auténtico sobre Jesús» (DV 19), formulación donde se nota la ausencia de la palabra 'historia' por su posible ambigüedad y por esto se insiste en una transmisión fiel a «lo verdadero y auténtico sobre Jesús».

De esta forma, el Vaticano II propone, una interpretación de la historicidad de los Evangelios no en sentido literalista o fundamentalista, sino en la clave habitual del momento en que fueron escritos que no era realizar una crónica puntual y detallada, como quiere la moderna ciencia histórica, sino con la intención de comunicar lo verdadero y lo auténtico que Jesús hizo y enseñó ${ }^{15}$. Es, pues, de esta forma que los Evangelios, y análogamente toda la Escritura, guardan y transmiten la verdad y por tanto son fidedignos, ya que gracias a ser palabra inspirada comunican «la verdad para la salvación» (DV 11), como objetivo central de su ser Palabra de Dios.

Seguramente la poca profundización de esta perspectiva ha comportado que desde hace ya años se observe la falta de tratados sobre la inspiración y, por otro lado, se subraye que su causa probablemente es la cuestión de la relación entre exégesis y teología, cuestión no solucionada en toda la etapa posconciliar y a la cual quiere colaborar esta Exhortación Apostólica dado que fue un tema fundamental en el Sínodo previo.

6. La respuesta del hombre (VD 22-28) se trata de una breve síntesis teológico-fundamental -que recuerda las perspectivas de K. Rahner, J. Alfaro...-que parte del «primado de la Palabra de Dios dirigida al hombre» (VD 22), la cual cumple una doble función: «purificar y perfeccionar los deseos auténticos del hombre». Doble dimensión que recuerda la doble función del don de Dios de la gracia en el hombre que «cura» (la gratia sanans de san Agustín) y que «eleva y perfecciona»

14. Cf. M. SeCKLeR, «¿Qué es la 'palabra de Dios'?», en AA.VV., Fe cristiana y Sociedad Moderna 2, Madrid 1984, 82-96.

15. Precisa J. A. Fitzmyer: «obsérvese que la fórmula lo verdadero y auténtico sobre Jesús ('vera et sincera de lesu') no se puede equiparar sin más con la verdad histórica», Catecismo cristológico, Salamanca ${ }^{3} 1997,156, n^{\circ} 3$. 


\section{Salvador Pié-Ninot}

(la gratia elevans de los escolásticos; cf. LG 13.16). Por esto se afirma «que sólo Dios responde a la sed que hay en el corazón de todo ser humano» y se cita una preciosa reflexión de nuevo de Buenaventura: «el fruto de la Sagrada Escritura no es uno cualquiera, sino la plenitud de la felicidad eterna» (VD 23). Esta es la razón por la cual en el diálogo con Dios se usan también sus palabras, particularmente los Salmos, «confirmando el carácter dialogal de toda la revelación cristiana» (VD 24), que desemboca en su acogida por la fe, descrita sucintamente como encuentro con una Persona que implica también «su cuerpo que es la Iglesia..., por eso nuestro acto de fe es al mismo tiempo un acto personal y eclesial» (VD 25). Por eso el pecado es no escuchar la Palabra de Dios (VD 26).

7. Mariología y teología de la Palabra de Dios (VD 27-28): se concluye con una referencia a María: «Madre del del Verbo de Dios» y «Madre de la fe», y de forma muy sugerente, se pide que se estudie la relación entre Mariología y Palabra de Dios, teniendo presente «la familiaridad de María con la Palabra de Dios, que resplandece con particular brillo en el Magnificat... 'completamente tejido por los hilos tomados de la Sagrada Escritura, de la Palabra de Dios' (Deus caritas est, $\left.n^{\circ} 41\right) \ldots$ Así pues, todo lo que le sucedió a María puede sucerderle ahora a cualquiera de nosotros en la escucha de la Palabra y en la celebración de os sacramentos» (VD 28).

8. La interpretación de la Escritura (VD 29-49), esta es la sección más extensa de toda la VD introducida por una solemne afirmación: «la Iglesia, lugar originario de la interpretación de la Biblia» (VD 29), así, como la aseveración de «la Escritura, como el alma de la teología» (VD 31, cita de DV 24); a su vez, recoge la intervención de Benedicto XVI en el Sínodo que comenta lo tres criterios para una lectura teológica de la Escritura que según DV 12 son: 1) unidad de toda la Escritura o exégesis canónica; 2) Tradición viva; 3) analogía de la fe...; teniendo presente la necesidad de operar siempre los dos niveles metodológicos de su lectura: el histórico-crítico y el teológico (VD 34). Un amplio testimonio de los santos cierra esta parte (VD 48-49).

* Nota sobre la interpretación de las Escritura: no sólo es la sección más extensa sino también la más viva de toda la Exhortación, ya que trata de la relación no siempre fácil entre exégesis y teología. El eje teológico que la preside y la informa es la «Cristología de la Palabra» (VD 11-13). Por esta razón, el sentido espiritual es visto desde esta perspectiva: ya que lee la Biblia «en el contexto del misterio pascual de Cristo» (VD 37, que cita el documento de la PCB de 1993, sobre La Interpretación de la Biblia en la Iglesia); más aún, se afirma que «toda la divina Escritura es un solo libro y este libro es Cristo» (VD 39), de ahí «la originalidad de la lectura cristológica del Antiguo Testamento, ya que éste es profecía del Nuevo Testamento, y el mejor comentario al Antiguo es el Nuevo» (VD 41).

Esta perspectiva claramente está tomada de la Dei Verbum: por un lado, se trata de explicitar por qué el Vaticano II trató primero la Tradición eclesial, en su capítulo II, y después, como un elemento clave de su interior, la Escritura, en los subsiguientes capítulos 
del III al VI. Algo que suele olvidarse y que De Lubac comentó con tino: «Hubo quienes vieron en la Dei Verbum principalmente, por no decir exclusivamente, un documento sobre la Biblia. Y, sin embargo, su mismo título y la disposición de sus capítulos nos están diciendo otra cosa. Salta a la vista que las palabras Dei Verbum que señalan el principio de la Constitución al mismo tiempo que objeto no designan la Escritura. Hemos visto que para el Concilio la «palabra de Dios» abarca mayores dimensiones: más extensión y más profundidad... Por eso el progreso esencial que ha venido a consagrar la DV es, ante todo, el progreso de la teología fundamental -que es también teología de la Escritura-» ${ }^{16}$.

El segundo aspecto, procedente de la Dei Verbum en su capítulo IV sobre el Antiguo Testamento, ha encontrado una lúcida resonancia en esta etapa posconciliar en la teología tal como K. Rahner atestigua así: «como pasado 'prehistórico' de la nueva y eterna alianza e la que ha desembocado el Antiguo Testamento, éste sólo puede interpretarse adecuadamente desde la nueva alianza, pues su verdadera esencia únicamente se descubre (cf. 2Cor 3, 14) en la revelación de su 'término final' (Rom 10, 4). Una consideración meramente 'histórico-religiosa' del Antiguo Testamento equivaldría al desconocimiento de su carácter sobrenatural ${ }^{17}$. En cambio, debe constatarse que tal perspectiva se encuentra casi ausente en los manuales o tratados de la Biblia.

En estos últimos años dos son las perspectivas que se están desarrollando para tener presente esta interpretación creyente de la Biblia. Por un lado, la emergencia del estudio en la exégesis de la llamada "historia de los efectos del texto» o Wirkungsgeschichte, es decir, el estudio de la forma en que ha sido interpretado y acogido un texto a través de la historia, método presentado por el documentoya citado de la PCB, La interpretación de la Biblia en la Iglesia, I.C.3. Siguiendo esta estela se sitúa el importante comentario unitario católico-luterano alemán del NT, dirigido por E. Schweizer y R. Schnackenburg ${ }^{18}$. La segunda perspectiva es la publicación, aún muy escasa, de teologías bíblicas globa$\operatorname{les}^{19}$, así como de comentarios patrísticos a los diversos libros de la Biblia ${ }^{20}$.

II. La Segunda parte: Verbum in Ecclesia: "La Palabra en la Iglesia» (Jn 1, 12) se inicia con una breve referencia eclesial a partir del texto del prólogo de Juan 1, 11-14 (VD 50) y de una reflexión sobre la contemporaiedad de Cristo en la vida de la Iglesia (VD 51), para entrar en la segunda sección más amplia de toda la Exhortación (VD 52-71):

1. "La liturgia, lugar privilegiado de la Palabra de Dios» (VD 52), donde se presenta un práctico vademécum de tipo concreto - sección que es comentada en un artículo específico en este mismo número de la revista-. Nótese, por su

16. «Conclusión sobre DV cap. I», en B.-D. DupuY (ed.), Revelación divina I, Madrid 1970, 325.

17. «Antiguo Testamento»: Sacramentum Mundi 1, 179-187.186.

18. Cf. entre sus comentarios más relevantes: R. ScHNACKENBURG, Der Brief an die Epheser, Zürich 1982; U. LUZ, El Evangelio según san Mateo I-IV (1985-2001), Salamanca 19932005, y F. Bovon, El Evangelio según san Lucas I-IV (1989-2009), Salamanca 1995-2010.

19. Cf. entre los pocos proyectos globales, los sugerentes de W. BRUEGGEMANN, Teología del Antiguo Testamento, Salamanca 2007, y de G. SEgalLA, Teologia biblica del Nuovo Testamento, Torino 2006.

20. Cf. la útil colección: La Biblia comentada por los Padres de la Iglesia, Madrid 2000ss. 


\section{Salvador Pié-Ninot}

mayor carga teológica, la afirmación de la sacramentalidad-como expresión de 'performatividad'- de la Palabra de Dios (VD 53.56), hasta ahora no afirmada tan ampliamente en un documento magisterial ${ }^{21}$; y, en segundo lugar, la cuestión del «ministerio del lectorado como ministerio laical» (VD 58).

También se afronta una cuestión, que fue notablemente citada en el Sínodo, como es la homilía (VD 59s). En ella se recoge la Proposición sinodal $n^{\circ} 15$, con la tres preguntas recogidas en VD 59, provenientes de la brillante intervención que tuvo en el Sínodo, Mons. R. Blázquez, obispo de Bilbao en aquel momento, con estas preguntas: «¿qué dicen las lecturas proclamadas? ¿qué me dicen personalmente? ¿qué debo decir a la comunidad, teniendo en cuenta su situación concreta?». Dada la importancia de la cuestión se recoge la iniciativa sinodal sobre un posible «Directorio homiliético» (VD 60).

* Nota sobre la sacramentalidad de la Palabra de Dios: su fundamentación se inicia con la relación entre Palabra de Dios y Eucaristía (VD 54), partiendo de Jn 6 y Lc 24, y reafirmando su íntima unidad según el concilio Vaticano II (SC 48.51.56; DV 21.26; AG 6.15; PO 18; PC 6), explicitada por la cita clásica medieval de que «la Escritura de Dios también se considera Cuerpo de Cristo» (Waltramus, s. XII; citado en, VD 54). Se sigue con la forma de presentación del Misal Romano al recordar como: «la Iglesia honra con una misma veneración, aunque no con el mismo culto, la Palabra de Dios y el misterio eucarístico» (Ordenación de las lecturas de la Misa, n 10: VD 55).

Finalmente, se afronta más directamente la «sacramentalidad de la Palabra» (VD 56) con una precisión teológica notable desarrollada con estos puntos centrales: «en el origen de la sacramentalidad de la Palabra de Dios está precisamente el misterio de la encarnación (Jn 1, 14)... De este modo, la sacramentalidad de la Palabra se puede entender en analogía con la presencia real de Cristo bajo las especies del pan y del vino consagrados (cf. CEC, 1373s.)... La proclamación de la Palabra de Dios en la celebración comporta reconocer que es Cristo mismo quien está presente y se dirige a nosotros (cf. SC 7)... Cristo realmente presente en las especies del pan y del vino, está presente de modo análogo también en la Palabra proclamada en la liturgia. Por tanto, profundizar en el sentido de la sacramentalidad de la Palabra de Dios puede favorecer una comprensión más unitaria del misterio de la revelación en «obras y palabras íntimamente ligadas» (DV 2), favoreciendo la vida espiritual de los fieles y la acción pastoral de la Iglesia».

* Nota sobre el ministerio de lectorado, también para las mujeres: la VD, al tratar de la primera y segunda lectura que «las proclama el lector encargado, hombre o mujer», reafirma «el ministerio del lectorado como ministerio laical» (VD 58), y así sitúa la propuesta sinodal sobre la posibilidad de un ministerio femenino (Proposición $n^{\circ} 17$ ), teniendo presente la contribución del 'genio femenino' (según el texto citado de Juan Pablo II) al conocimiento de la Escritura (VD 85). Se trata, pues, de poder conferir un ministerio «instituido» y no sólo de que puedan leer, servicio que no solamente es permitido sino que se realiza ya ampliamente.

21. Expresión ya citada por BENEDICTO XVI, Spe salvi, 2007, ns.5.10; cf. sobre la sacramentalidad, nuestros, «Teología de la Palabra de Dios e Iglesia», Gregorianum 89 (2008) 362366, y «Palabra de Dios y Liturgia», Phase 287-288 (2008) 551-575. 
En efecto, Pablo VI reformó las antiguas «órdenes menores», conservando únicamente el lectorado y el acolitado, aclarando que se trata de una 'institución' y no de una 'ordenación' de unos ministerios previos al diaconado reservados a los hombres. La palabra «institución» comporta tres aspectos: 1) un encargo oficial o nombramiento, habitualmente a través de un cierto rito; 2) una responsabilidad más precisa y estricta; y 3) una estabilidad y permanencia en el servicio. El Sínodo con el auspicio de poder «instituir el ministerio del lector a las mujeres» proponía un cambio de esta legislación eclesial para reconocer más 'oficialmente' este servicio que tantas mujeres realizan en la Iglesia. La VD 58, complementada con la VD 85, deja el camino abierto a tal tipo de desarrollo institucional auspiciado por el Sínodo 22 .

2. La Palabra de Dios en la vida de la Iglesia: de nuevo se insiste en la perspectiva cristológica así: «expreso el vivo deseo de que florezca una nueva etapa de mayor amor a la Sagrada Escritura de manera que, mediante la lectura orante y fiel a lo largo del tiempo, se profundice la relación con la persona de Jesús» (VD 72), y para esto se propone «la animación bíblica de la pastoral» (VD 73), «la dimension bíblica de la catequesis» (VD 74), «la formación bíblica» (VD 75...) y el amplio campo de las vocaciones (VD 77-83): ministros ordenados; candidatos al Orden sagrado; vida consagrada; fieles laicos a los que conviene darles «oportunidades formativas» (VD 84) y matrimonio y familia que en la Palabra de Dios encuentre «su identidad» (VD 85).

3. "Lectura orante de la Sagrada Escritura y 'lectio divina'» (VD 86-87): se trata del método estrella del Sínodo, unido estrechamente a la liturgia (VD 86), que se describe con sus cuatro pasos clásicos surgidos de la vida monástica: lectura, meditación, oración y contemplación, al que se añade como conclusión, la acción, dado que su uso habitual va dirigido a un público mucho más amplio y no se limita a la vida monástica, donde se forjó. Cierran dos puntos: uno, sobre la plegaria mariana (VD 88) y el otro, sobre Tierra Santa propuesta brillantemente por Pablo VI como «Quinto Evangelio» (VD 89).

* Nota sobre la lectura orante o 'lectio divina': método tratado ya en el Instrumentum Laboris $n^{\circ} 38$, en el Mensaje al Pueblo de Dios, $n^{\circ}$ 9, y en la Proposición sinodal, $n^{\circ} 22$, que enumera otras formas similares como «los ejercicios espirituales en la vida cotidiana; Seven Steps en África y otros lugares; diversos métodos de oración compartir en familia y en comunidades eclesiales de base, etc.». La expresión lectio divina deriva de una fórmula de Orígenes, "tê theia anagnôsei», entendida como un indagar el texto para dis-

22. Cf. el clásico Y. CongAR, «Los ministerios en la Iglesia», Seminarios 65/66 (1977) 359362, y nuestro, «Los ministerios confiados a los laicos», Phase 224 (1998) 133-153; no se puede negar que la cuestión era delicada, teniendo presente sus posibles interpretaciones en clave de 'poco' o de 'demasiado', pero el Sínodo optó por una 'via media' realista como signo de real 'reconocimiento' de la relevancia del servicio de las mujeres en la Iglesia y en este caso en el anuncio y testimonio de la Palabra de Dios, tal como atestigua la proposición, $\mathrm{n}^{\circ}$ 17, citada explícitamente en VD 85, en el contexto presentado por VD 58. 


\section{Salvador Pié-Ninot}

cernir su sentido a diversos niveles. Posteriormente, las reglas monásticas de Pacomio, Agustín, Basilio y Benedicto la incorporan en clave más orante. Su primer sistematizador fue el cartujano de Grenoble, Guigo II († 1188) con cuatro grados: lectura, meditación, oración y contemplación.

He aquí su descripción de estos cuatro grados: «un día, ocupado en el trabajo manual, comencé a pensar en la actividad espiritual del hombre. Y se me ocurrieron, de pronto, cuatro escalones o peldaños espirituales, o sea, la lectura, la meditación, la oración y la contemplación... La lectura es un examen detenido de la Escritura con espíritu atento. La meditación es una operación reflexiva de la mente que investiga, con la ayuda de la razón, el conocimiento de la verdad oculta. La oración es una ferviente elevación del corazón hacia Dios para alejar los males y recibir los bienes. La contemplación es una elevación por encima de sí misma de la mente suspendida en Dios, que degusta las alegrías de la eterna dulzura» ${ }^{23}$. El añadido de la acción viene explicado justamente al afirmar que «la lectio divina no termina su proceso hasta que no llega a la acción, que mueve la vida del creyente a convertirse en don para los demás por la caridad» (VD 87).

III. Tercera parte: "La Palabra al mundo» (Jn 1, 18): «A Dios nadie le ha visto jamás. El Hijo único, que está en el seno del Padre, es quien lo ha dado a conocer».

1. «La misión de la Iglesia: anunciar la Palabra de Dios al mundo» (VD 9098): se encuentra aquí un breve desarrollo teológico sobre qué significado tiene la Palabra de Dios, definida en clave cristológica como «palabra de la Esperanza» (VD 91). Y se explica que «el hombre necesita la 'gran esperanza' para poder vivir el propio presente, la gran esperanza que es «el Dios que tiene un rostro humano y que nos ha amado hasta el extremo (Jn 13, 1)» (VD 91). Por eso la persona de Jesucristo es el mismo Reino de Dios (la Autobasileia), como recuerda sugestivamente el texto citado de Orígenes (VD 93). Esta formulación se complementa con la doble afirmación sobre la definitividad como característica de la Palabra de Dios, presente al inicio (VD 11) y al final de la Exhortación cuando se afirma que es «la Palabra definitiva que Dios dice a la humanidad, al cosmos y a la historia» (VD 121).

Después de recordar que «todos los bautizados son responsables del anuncio» (VD 94), es de relevancia el número dedicado a la Nueva Evangelización (VD 96, retomado en el número conclusivo de VD 122), «de los bautizados, pero no suficientemente evangelizados», así como de las «naciones un tiempo ricas en fe y vocaciones que van perdiendo su propia identidad, bajo la influencia de una cutura secularizada» (VD 96). Se percibe aquí el gran interés del Papa so-

23. Cf. el texto en el gran especialista y experto sinodal, E. Bianchi, Orar la Palabra (or.1974), Burgos 2000, 127s; entre la inmensa bibliografía, cf. H. RAGUER, Lectio divina, cuaderno Phase, n. 94, Barcelona 1999; C. Mesters, Lectura orante de la Biblia, Estella 2000; G. ZeVINI, La lectio divina en la comunidad cristiana, Estella 2005; F. ConTRERAs, Leer la Biblia como Palabra de Dios. Claves teológico-pastorales de la lectio divina en la Iglesia, Estella 2007. 
bre esta cuestión que le ha llevado a crear la única novedad por ahora de su Pontificado en la Curia Romana, como es el Pontificio Consejo para la Nueva Evangelización (año 2010).

Una bella síntesis sobre el testimonio y su credibilidad -palabra usada sólo aquí y dos veces (VD 97-98) - cierra esta sección con una brillante cita de la Evangelii Nuntiandi (1975), 22, donde se articula testimonio y anuncio con una formulación paradigmática: «El Evangelio proclamado por el testimonio de vida deberá ser pues, tarde o temprano, proclamado por la palabra de vida. No hay Evangelización verdadera, mientras no se anuncie el nombre, la doctrina, la vida, las promesas, el reino, el misterio de Jesús de Nazaret, Hijo de Dios» (VD 98).

2. «Palabra de Dios y compromiso en el mundo» (VD 99-108): se enumeran atentamente los diversos ámbitos de compromiso de los cristianos en el mundo de hoy partiendo del «servid a Jesús en sus 'humildes hermanos' (Mt 25, 40)» (VD 99), que se desarrolla con estos acentos: el compromiso por la justicia (VD 100-101); la reconciliación y paz entre los pueblos (VD 102); la caridad efectiva (VD 103); los jóvenes (VD 104); los emigrantes (VD 105); los que sufren (VD 106); los pobres (VD 107), y la salvaguarda de la Creación (VD 108).

3. «Palabra de Dios y culturas» (VD 109-116): texto con un inicio significativo ya que formula que «el anuncio joánico referente a la encarnación del Verbo revela la unión indisoluble entre Palabra divina y las palabras humanas, por las cuales se nos comunica» (VD 109). Además, se sintetiza brillantemente, en una frase que ha consagrado el cardenal G. Ravasi, presidente del Pontificio Consejo para la Cultura, con este tenor: «la Biblia como un gran códice para las culturas» (VD 110), de ahí «la importancia de su conocimiento en la escuela y la universidad» (VD 111), "en las diversas manifestaciones artísticas, donde se deine a los artistas como 'los enamorados de la belleza'» (VD 112), su incidencia en «los medios de comunicación social, donde su subraya la importancia de no perder a pesar del internet «el contacto personal»! (VD 113); finalmente, merece atención «la inculturación» (VD 114), «la traducción y difusión de la Biblia» (VD 115) y el recuerdo de que «la Palabra de Dios supera los límites de las culturas..., para dejar espacio en nosotros a la presencia de Cristo» (VD 116).

4. «Palabra de Dios y diálogo interreligioso» (VD 117-120): brevemente se afronta este tema tan actual dado «el rápido proceso de globalización» (VD 117); se particulariza el diálogo entre cristianos y musulmanos, exhortando a «una covivencia pacífica y positiva» (VD 118); sobre las demás religiones -los judíos han sido tratados en VD 43, en el punto referido a la interpretación de la Escritura- y son citados especialmente: el Budismo, el Hinduismo y el Confucionismo (VD 119), conluyéndose con una exhortación al diálogo y al respeto a la libertad religiosa (VD 120). 
Conclusión (VD 121-124): cierra toda la Exhortación repitiendo la calificación de la Palabra de Dios como Palabra definitiva (VD 121, ya así VD 11), recordando la nueva evangelización que comporta una nueva escucha (VD 122, ya citada en, VD 96), repitiendo que la Palabra genera alegría (VD 123, ya presente en VD 2) y presentando a María como «Madre de la Palabra y de la Alegría», como modelo que hace posible la «familiaridad con la Palabra de Dios» (VD 124, donde resuena VD 27s.). Finalmente, con una bella paráfrasis de un texto de Apocalipsis, se renueva una invitación general «a todos los hombres, también los que se han alejado de la Iglesia, que han abandonado la fe o que nunca han escuchado el anuncio de salvación. A cada uno de ellos, el Señor les dice: 'Estoy a la puerta llamando: si alguien oye y me abre, entraré y comeremos juntos' (Ap 3, 20)» (VD 124). 